\title{
Distinct requirements for Ras oncogenesis in human versus mouse cells
}

\author{
Nesrin M. Hamad, ${ }^{1,4}$ Joel H. Elconin, ${ }^{1,4,5}$ Antoine E. Karnoub, ${ }^{3}$ Wenli Bai, ${ }^{1}$ Jeremy N. Rich, ${ }^{2}$ \\ Robert T. Abraham, ${ }^{1,6}$ Channing J. Der, ${ }^{3}$ and Christopher M. Counter ${ }^{1,7}$ \\ ${ }^{1}$ Departments of Pharmacology and Cancer Biology and Radiation Oncology and ${ }^{2}$ Department of Medicine, Division of \\ Neurology, Duke University Medical Center, Durham North Carolina 27710, USA; ${ }^{3}$ Department of Pharmacology, \\ Lineberger Comprehensive Cancer Center, University of North Carolina, Chapel Hill, North Carolina 27599, USA
}

The spectrum of tumors associated with oncogenic Ras in humans often differs from those in mice either treated with carcinogens or engineered to sporadically express oncogenic Ras, suggesting that the mechanism of Ras transformation may be different in humans. Ras stimulates primarily three main classes of effector proteins, Rafs, PI3-kinase, and RalGEFs, with Raf generally being the most potent at transforming murine cells. Using oncogenic Ras mutants that activate single effectors as well as constitutively active effectors, we find that the RalGEF, and not the Raf or PI3-kinase pathway, is sufficient for Ras transformation in human cells. Thus, oncogenic Ras may transform murine and human cells by distinct mechanisms, and the RalGEF pathway-previously deemed to play a secondary role in Ras transformation-could represent a new target for anti-cancer therapy.

[Key Words: Ras; RalGEF; transformation; tumorigenesis; human]

Received March 21, 2002; revised version accepted June 17, 2002.

Extracellular signals detected by cell-surface receptors can be transmitted to the cell by stimulating the conversion of the Ras oncoprotein from an inactive GDP-bound to an active GTP-bound state. In the GTP-bound state, Ras stimulates downstream targets, or effectors, which, in turn, affect numerous activities of the cell, such as proliferation, apoptosis, and differentiation (Shields et al. 2000). Mutated and constitutively activated forms of Ras are found in $30 \%$ of all human cancers (Bos 1989). Significant experimental and epidemiological evidence supports that such aberrant Ras activation plays a critical role in human oncogenesis. Consequently, there is considerable effort to develop inhibitors of the Ras-signaling pathway for use as novel anticancer drugs (Kloog and Cox 2000; Shields et al. 2000).

Ras transformation is mediated by interactions with multiple downstream effectors whose contribution to Ras transformation has been evaluated primarily in rodent fibroblast model cell systems. Substantial evidence from these studies supports the role of Raf serine/threonine kinases (c-Raf-1, A-Raf, and B-Raf) as key effectors and mediators of Ras-transforming activity. Raf kinases phosphorylate and activate the MEK1 and MEK2 dual

\footnotetext{
${ }^{4}$ These authors contributed equally to this work.

Present addresses: ${ }^{5} \mathrm{New}$ Mexico Oncology Consultants, Albuquerque, New Mexico 87102, USA; ${ }^{6}$ The Burnham Institute, La Jolla, California 92037, USA.

${ }^{7}$ Corresponding author.

E-MAIL count004@mc.duke.edu; FAX (919) 684-8958.

Article and publication are at http://www.genesdev.org/cgi/doi/10.1101/ gad.993902.
}

specificity kinases, which, in turn, phosphorylate and activate the ERK1/p44 and ERK2/p42 mitogen-activated protein kinases (MAPKs) (Kyriakis et al. 1992). The critical contribution of the Raf/MEK/ERK pathway to Ras transformation is shown by the ability of constitutively activated mutants of Raf or MEK to cause tumorigenic transformation of NIH 3T3 cells (Bonner et al. 1985; Stanton et al. 1989; Leevers et al. 1994; Stokoe et al. 1994). Additionally, dominant-negative mutants of Raf1, MEK, and ERK, as well as pharmacologic inhibitors of MEK, have been shown to effectively block Ras transformation in vitro or suppress tumorigenic growth of cancer cell lines in vivo (Kolch et al. 1991; Schaap et al. 1993; Cowley et al. 1994; Westwick et al. 1994; Khosravi-Far et al. 1995; Qiu et al. 1995; Monia et al. 1996; Sebolt-Leopold et al. 1999).

Perhaps the second best-characterized effector important for Ras transformation is phosphatidylinositol 3-kinase (PI3-kinase). Activated PI3-kinase, a lipid kinase, facilitates the conversion of phosphatidylinositol 4,5bisphosphate (PIP2) to phosphatidylinositol 3,4,5-trisphosphate (PIP3). PIP3 levels are elevated in Ras-transformed cells. Dominant-negative mutants of PI3-kinase can effectively block Ras transformation of NIH $3 \mathrm{~T} 3$ cells. Finally, whereas activated PI3-kinase alone cannot cause transformation of NIH 3T3 cells, activated variants of PI3-kinase can cooperate with activated Raf to cause synergistic transforming activity (Rodriguez-Viciana et al. 1997).

The third class of effectors with a role in Ras transformation are guanine nucleotide exchange factors (GEFs) 
for the Ral small GTPases, RalGDS, RGL, RGL2/Rlf, and RGL3 (Wolthuis and Bos 1999). Inhibition of these RalGEFs by expression of a dominant-negative Ral protein blocks Ras focus formation or hematogenous metastatic growth of specific cell lines (Urano et al. 1996; White et al. 1996; Lu et al. 2000; Ward et al. 2001). Furthermore, whereas constitutively activated variants of RalGEFs are not transforming in NIH 3T3 cells, their coexpression with activated Raf induced synergistic focus formation (Urano et al. 1996; White et al. 1996). Thus, although current evidence does not implicate RalGEFs as key players in Ras transformation, they may contribute to the process.

Activating mutations of Ras are found in humans in nearly all pancreatic cancers, one-half of colon and thyroid tumors, and one-third of lung tumors (Bos 1989). However, transgenic mice that model these sporadic Ras mutations do not give rise to the same tumors linked to Ras mutations of human cancer patients. In particular, these mice fail to form pancreatic, thyroid, or colon tumors (Johnson et al. 2001). Additionally, a divergent association of Ras mutations with distinct neoplasms is also seen when compared in humans and rodents. For example, whereas Ras mutations are strongly associated with the carcinogen-induced mammary carcinomas in mice and rats (Zarbl et al. 1985; Miyamoto et al. 1990), such mutations are rare in human breast cancers (Bos 1989). One interpretation of these results is that Rasmediated tumorigenic growth may display subtle, but important differences between mice and humans. We therefore wished to determine whether the mechanisms of Ras-induced transformation and tumorigenesis operate in a similar fashion in mice and humans.

One drawback of studying Ras-induced transformation in human cells is that ectopic expression of Ras causes cellular senescence in primary human cells (Serrano et al. 1997). However, we recently described that normal primary human cells can be converted to a tumorigenic state by the enforced expression of oncogenic (12V) HRas and two other genes, hTERT and the early region of SV40. hTERT is the catalytic subunit of telomerase (Nakamura and Cech 1998), which is essential to immortalize human cells (Bodnar et al. 1998; Counter et al. 1998; Vaziri and Benchimol 1998) and is illegitimately activated to restore telomerase activity in $85 \%$ of human cancers (Shay and Bacchetti 1997). The SV40 early region encodes the oncoproteins $\mathrm{T}$ and $\mathrm{t}-\mathrm{Ag}$, which transform mammalian cells through, in part, disrupting the functions of the tumor suppressor proteins p53 and Rb (Livingston 1992; Ludlow 1993) and the phosphatase PP2A (Sleigh et al. 1978; Rubin et al. 1982; Pallas et al. 1990; Hahn et al. 2002). SV40 DNA, virus, or the T-Ag oncoprotein have also been detected specifically in tumor, but not adjacent tissues, from a wide spectrum of cancers, potentially implicating this virus in the etiology of certain human tumors (Bergsagel et al. 1992; Carbone et al. 1994; Lednicky et al. 1995; Martini et al. 1996). Expression of the T-Ag gene, hTERT, and H-Ras $12 \mathrm{~V}$ in primary cultures of human fibroblasts, embryonic kidney, mammary epithelial, and astrocyte cells leads to the cre- ation of sarcomas (Hahn et al. 1999), carcinomas (Hahn et al. 1999; Elenbaas et al. 2001), and glioblastomas (Rich et al. 2001), respectively, suggesting that ectopic expression of these genes comprise a core set of changes required for tumor growth of human cells. Moreover, because oncogenic Ras is absolutely required for these cells to become tumorigenic, primary cultures of human cells expressing large and small $\mathrm{T}$-Ag and hTERT proteins provide a genetically defined system to circumvent the above limitation, allowing for the study of Ras-mediated oncogenesis in human cells. Although this system does not mimic the gradual selection of spontaneous mutations over time, it does allow one to delineate the contribution of specific genetic changes to the tumorigenic process, starting with primary human cells. Therefore, in this study, we utilized these human cell model systems to evaluate the role of specific effectors in mediating Ras transformation. Our results reveal a striking difference in the contribution of distinct effector pathways to Ras transformation in rodent and human cells, and suggest that RalGEF may play a key role in Ras-mediated human oncogenesis.

\section{Results}

Ras12V37G, but not Ras12V35S, transforms human cells

As a first step to elucidate the signaling pathways through which Ras transforms human cells, we sought to determine which effectors of Ras are essential for the transformation of primary human cells. Activated Ras binds its downstream effectors through the core effector domain (residues 32-40). Specific missense mutations in this domain of H-Ras12V that selectively impair the binding and activation of Raf, PI3-kinase, and RalGEFs have been utilized widely to delineate the role of the specific effector pathways in Ras function. Oncogenic H-Ras12V with the mutations T35S, Y40C, or E37G bind to and activate primarily Raf, PI3-kinase, or RalGEFs, respectively. In NIH $3 \mathrm{~T} 3$ cells, the H-Ras12V35S mutant shows much greater potency than either the $37 \mathrm{G}$ or $40 \mathrm{C}$ mutants, providing important evidence that Ras transformation of rodent fibroblasts is mediated primarily through Raf (White et al. 1995; Khosravi-Far et al. 1996; Shields et al. 2000). Therefore, we utilized H-Ras $12 \mathrm{~V}$ effector domain mutants to evaluate the importance of Raf, PI3-kinase, and RalGEFs to Ras transformation of human cells.

Prior to evaluating the Ras effector domain mutants in human cells, we verified that our expression vectors for each effector mutant exhibited the differential ability to transform NIH 3T3 cells, as has been described in previous studies (White et al. 1995; Khosravi-Far et al. 1996; Shields et al. 2000). The three described effector domain mutants of $\mathrm{H}-\mathrm{Ras} 12 \mathrm{~V}$, oncogenic $\mathrm{H}-\mathrm{Ras} 12 \mathrm{~V}$ as a positive control, the null vector, or nontransforming H-Ras as dual negative controls were stably introduced into NIH 3T3 mouse fibroblasts. Immunoblot analysis for ectopic Ras in extracts isolated from the resultant polyclonal 
populations revealed a similar amount of this protein in each of the Ras-infected cells (Fig. 1A), presumably at levels higher than typically observed in cancer cells. Cells were next assayed for growth in soft agar. This assay is one of the most rigorous tests of cellular transformation in vitro and provides the best in vitro correlate to tumorigenic growth potential. Additionally, polyclonal populations were assayed immediately after infection to limit the possibility of cells with sporadic mutations skewing the transformation properties of the culture. As expected, NIH 3T3 cells failed to grow in soft agar unless oncogenic, but not wild-type, Ras was expressed. Moreover, as reported by others, Ras12V35S, which activates Raf but not PI3-kinase or RalGEFs (White et al. 1995; Khosravi-Far et al. 1996; RodriguezViciana et al. 1996), was the most highly transforming mutant when expressed in these cells (Fig. 1B).

Having shown that the Ras effector domain mutants function as expected on the basis of the most stringent criteria - biological transformation - we next introduced by retroviral infection the expression vectors encoding the same effector domain mutants and appropriate positive and negative control vectors into human cells. We chose to first test primary human embryonic kidney (HEK) epithelial cells that ectopically express $h T E R T$ and the $T-A g$ gene (encoding large and small $\mathrm{T}-\mathrm{Ag}$ ). These HEK-HT cells are ideal for assaying Ras-induced oncogenesis, because the addition of oncogenic Ras renders them transformed, as assessed by growth in semisolid medium, and tumor formation when injected into immunocompromised mice (Hahn et al. 1999). After infection, the cells were assayed for H-Ras $12 \mathrm{~V}$ expression by immunoblot analysis and for transformation by the soft agar assay. We found that ectopic Ras was expressed at similar levels in each of the Ras-infected cells (Fig. 1A). Surprisingly, the transformation profile of human cells by use of the identical effector domain mutants was quite different from that observed in NIH 3T3 cells. Ras12V35S, which activates Raf but not PI3-kinase or RalGEFs, did not support anchorage-independent growth of the human HEK-HT cells (Fig. 1B), despite the fact that this protein is the most potent effector mutant of Ras12V in the murine NIH 3T3 cell-transformation assay. Rather, Ras12V37G, which activates RalGEFs but not Raf or PI3-kinase (White et al. 1996; Rodriguez-Viciana et al. 1997; Wolthuis and Bos 1999), was the only effector domain mutant that yielded transformed growth with human cells (Fig. 1B). These results indicate that oncogenic Ras utilizes different signaling pathways in the transformation of murine NIH 3T3 versus human HEK-HT cells.

\section{Species variation underlies the differences in Ras-induced transformation between murine and human fibroblasts}

We envisioned three differences between NIH 3T3 and HEK-HT cells that could account for the dramatic discrepancies in Ras-induced transformation between these cells. First, the difference may stem from the fact that these cells are of different lineage (mesoderm vs. ectoderm). Second, the expression of the $T-A g$ gene in HEKHT cells, but not NIH 3T3 cells, may be a factor, especially in light of the fact that the alternatively spliced product small t-Ag can indirectly affect MAP-kinase function (Rubin et al. 1982). Although the HEK-HT cells were also infected with an hTERT-encoding retrovirus to restore telomerase activity, this gene was not considered
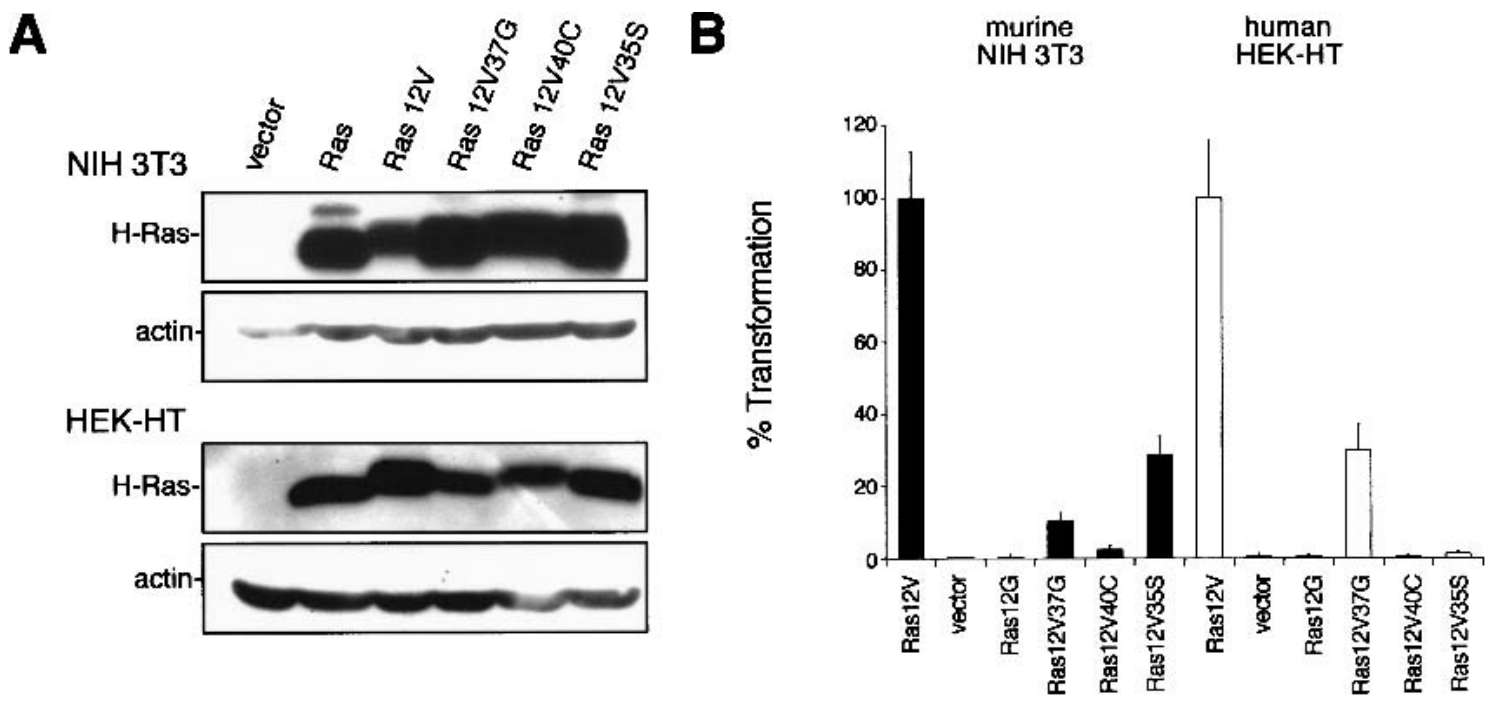

Figure 1. Ras12V37G transforms human cells. (A) Expression of Ras mutants was confirmed in NIH 3 T3 or HEK-HT cells stably infected with retroviruses encoding the described FLAG-tagged H-Ras cDNAs or with a vector or H-Ras control, by immunoblotting with an anti-FLAG antibody. Actin levels serve as a loading control. (B) Anchorage-independent growth of NIH 3T3 (black bars) or human HEK-HT (white bars) cells expressing the described constructs, calculated from the average number of colonies observed from three plates and expressed as the percent of colonies observed in Ras12V-transformed cells. A total of 50,000 Ras $12 \mathrm{~V}$-transformed NIH $3 \mathrm{~T} 3$ or HEK-HT cells yielded $380 \pm 50$ or $289 \pm 47$ colonies in soft agar, respectively. 
a confounding factor, as NIH 3T3 cells retain expression of the endogenous gene and are telomerase positive (Greenberg et al. 1998). Third, species differences may be important, because NIH 3T3 cells are murine, whereas HEK-HT cells are human.

To directly test whether species variation underlies the difference in transformation, we created identically matched pairs of transformed human and murine cells from the same cell type. Specifically, we isolated normal primary fibroblasts from mice and humans and stably introduced the exact same $T$ - $A g$ gene into both. Equivalent T-Ag expression was confirmed in both the human and murine fibroblasts by immunoblotting with an antiT-Ag antibody (Fig. 2A). Additionally, because cultured murine fibroblasts are telomerase positive /Chadeneau et al. 1995; Greenberg et al. 1998), hTERT was stably introduced into the human cells to restore telomerase activity (data not shown; Hahn et al. 1999). The cells were next infected with a vector control retrovirus or one encoding oncogenic H-Ras, or the three effector domain mutants. Immunoblot analysis for ectopic H-Ras expression verified that the different $\mathrm{H}-\mathrm{R} a \mathrm{~s} 12 \mathrm{~V}$ proteins were expressed at similar levels (Fig. 2B). As before, the polyclonal populations were immediately assayed for anchorage-independent growth. We found that T-Ag expressing primary murine fibroblasts behaved as NIH 3T3 cells, in which Ras12V35S was still the most potent effector domain mutant at promoting transformation (Fig. 2C). We also repeated the experiment with fibroblasts isolated from a different mouse. Specifically, primary cultures of murine fibroblasts were stably infected with retroviruses encoding $\mathrm{T}-\mathrm{Ag}$, and Ras12V or the aforementioned effector domain mutants and assayed for anchorage-independent growth. Although the differences between the various effects of the mutants on anchorage-independent growth was less pronounced, Ras12V35S was the most potent effector domain mutant in this transformation assay (Fig. 2D). On the other hand, the human fibroblasts expressing T-Ag and hTERT resembled HEK-HT cells, in which Ras12V37G was again the only effector domain mutant capable of supporting growth in soft agar (Fig. 2C). Thus, the transforming potential of Ras12V37G in human cells cannot be ascribed to either cell type or expression of large or small $\mathrm{T}$-antigens. The simplest interpretation of these data is that the observed discordance in Ras transformation is due to a fundamental difference between mouse and human cells.

\section{Transformation profiles of Ras effector mutants are not cell-type specific in human cells}

The transformation potential of Ras effectors has been reported to vary depending on cell type in rodents. For example, an activated version of Raf1 promotes tumorigenic growth of NIH 3T3 fibroblasts (Cowley et al. 1994; Mansour et al. 1994), whereas RIE-1 epithelial cells are
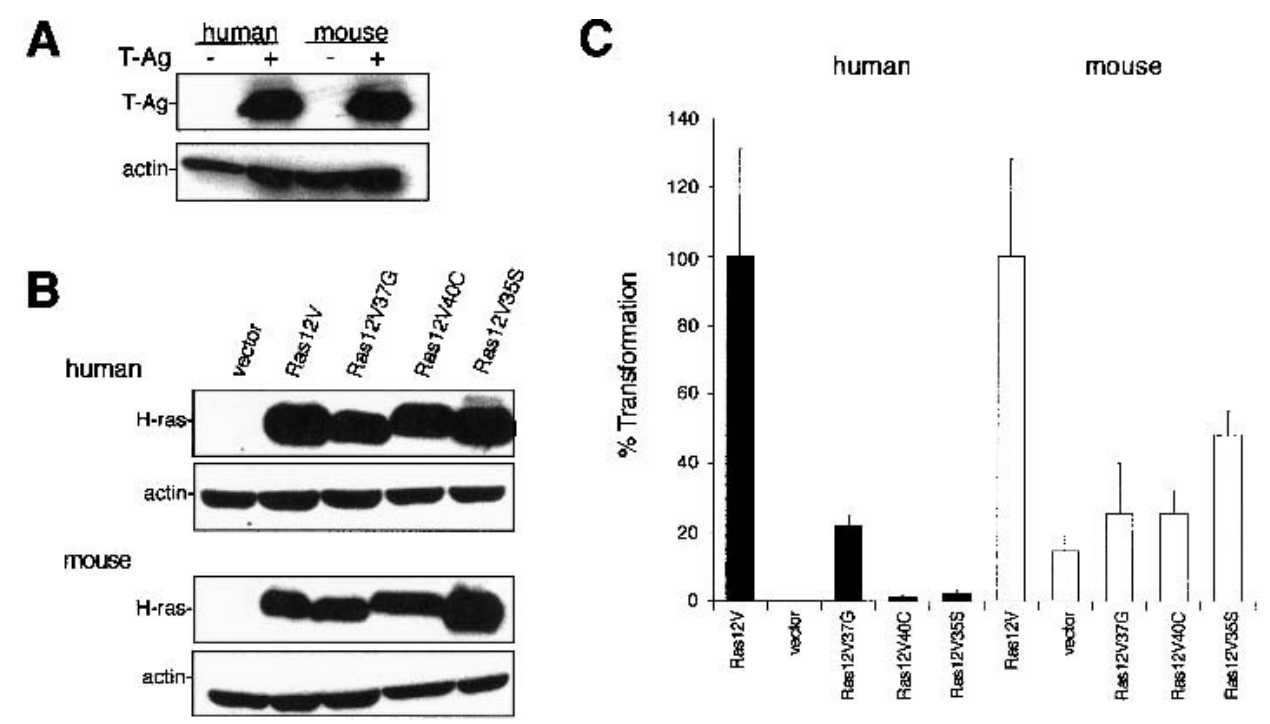

D

Figure 2. Ras-induced transformation is different in human vs. murine cells. (A) Expression of T-Ag was confirmed in human and murine fibroblasts stably infected with a retrovirus encoding the $T$ - $A g$ gene by immunoblotting with an anti-T-Ag antibody. Actin serves as a loading control. $(B)$ Expression of Ras mutants was confirmed in T-Ag expressing murine and human fibroblasts (the latter of which also ectopically express hTERT) stably infected with retroviruses encoding the described FLAG-tagged H-Ras cDNAs or with a vector control, by immunoblotting with an anti-FLAG antibody. Actin levels serve as a loading control. $(C)$ Anchorage-independent growth of the aforementioned T-Ag-expressing human (black bars) and murine (white bars) fibroblasts, calculated from the average number of colonies observed from three plates and expressed as the percent of colonies observed in Ras12V-transformed cells. A total of 50,000 Ras12V-transformed human or mouse fibroblasts yielded $320 \pm 100$ or $481 \pm 135$ colonies in soft agar, respectively. (D) Anchorage-independent growth of a different independently derived mouse fibroblast cell strain stably infected with constructs encoding T-Ag and the described H-Ras mutants, calculated from the average number of colonies observed from three plates and expressed as the percent of colonies observed in Ras12V-transformed cells. A total of 50,000 Ras12V-transformed mouse fibroblasts yielded $497 \pm 64$ colonies in soft agar. 
resistant to transformation by this protein (Oldham et al. 1996). Thus, it is possible that the observed transformation of human cells by only the Ras effector mutant that activates RalGEFs may be restricted to specific cell types. However, we showed that both human fibroblasts and HEK cells expressing T-Ag and hTERT behaved identically with respect to Ras transformation. Both cell types grew in soft agar only in the presence of the $37 \mathrm{G}$ effector domain mutant of H-Ras12V (Figs. 1B and 2C). Moreover, we found identical results with a third, completely different cell type. Human astrocytes expressing hTERT and the $T-A g$ gene (Rich et al. 2001) were stably infected with a control retrovirus or one encoding H-Ras12V or the effector domain mutants (Fig. 3A) and assayed for growth in soft agar. Again, the $37 \mathrm{G}$ effector domain mutant was the only variant of Ras $12 \mathrm{~V}$ that retained the ability to transform astrocytes (Fig. 3B). Given that HEK cells are derived from ectoderm, fibroblast from mesoderm, and astrocytes from neuroectoderm, we suggest that the $37 \mathrm{G}$ mutant of $\mathrm{H}-\mathrm{Ras} 12 \mathrm{~V}$ in the presence of the $T-A g$ gene and hTERT may promote the

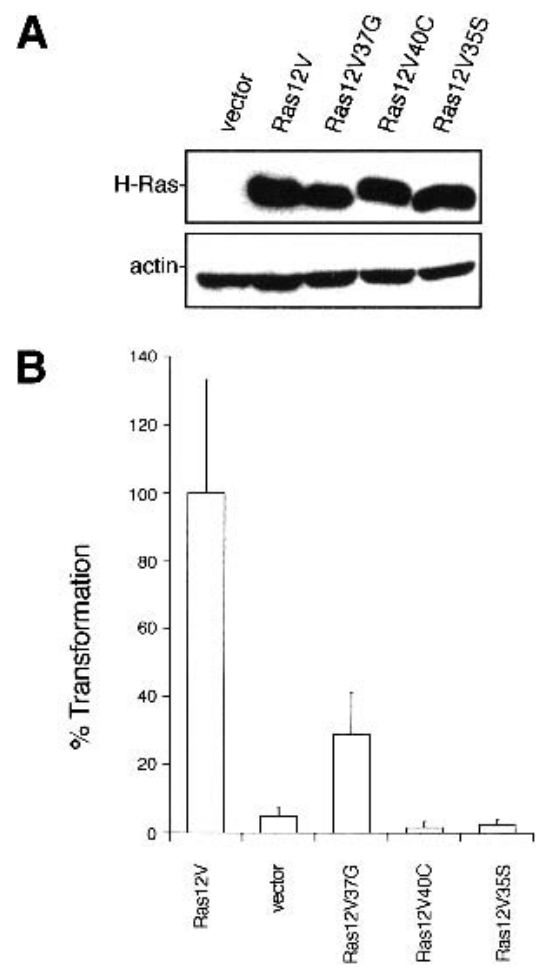

Figure 3. Ras12V37G transforms human astrocytes. (A) Expression of Ras mutants was confirmed in hTERT, T-Ag-expressing human astrocytes stably infected with retroviruses encoding the described FLAG-tagged H-Ras cDNAs or with a vector control, by immunoblotting with an anti-FLAG antibody. Actin levels serve as a loading control. (B) Anchorage-independent growth of the aforementioned hTERT, T-Ag human astrocytes expressing the described constructs, calculated from the average number of colonies observed from three plates and expressed as the percent of colonies observed in Ras $12 \mathrm{~V}$-transformed cells. A total of 50,000 Ras12V-transformed human astrocytes yielded $120 \pm 40$ colonies in soft agar. growth transformation of a diverse variety of human cell types. The signaling pathway emanating from Ras12V37G may therefore be a general requirement for Ras transformation of human cells.

\section{Activation of neither the MAP-kinase nor the PI3-kinase pathway is sufficient to transform human cells}

The observation that expression of Ras12V35S failed to transform a wide spectrum of human cells argues that, unlike murine fibroblasts, activation of Raf and subsequently the MAP-kinase pathway is alone insufficient to transform human cells. To directly evaluate this possibility, an amino-terminally truncated and constitutively active version of Raf1, $\Delta$ Raf1-22W (Stanton et al. 1989), was stably expressed in HEK-HT cells (Fig. 4A). We determined that HEK-HT cells stably overexpressing $\Delta$ Raf1-22W possessed elevated levels of phosphorylated and activated ERK that were comparable with the elevated level seen in Ras-transformed HEK-HT cells. In contrast, there was no increase in Akt phosphorylation, a downstream target of activated PI3-kinase, indicating the specific activation of the ERK pathway by $\Delta$ Raf122W (Fig. 4B). Having shown that $\Delta$ Raf1-22W caused sustained up-regulation of ERK in HEK-HT cells, we next assayed the ability of these cells to grow in soft agar. In accordance with our observations with Ras12V35S, the resultant cells failed to form colonies in semi-solid medium (Fig. 4C).

We similarly confirmed that activation of the PI3-kinase pathway is not transforming. Specifically, HEK-HT cells were infected with a retrovirus encoding p110CAAX, a membrane-targeted and constitutively activated version of the p110 $\alpha$ catalytic subunit of PI3-kinase (Rodriguez-Viciana et al. 1997). We verified that the HEK-HT cells stably expressed p110-CAAX and showed up-regulated levels of activated Akt, but not ERK (Fig. 4A,B). Similar to our results with Ras12V40C, activation of the PI3-kinase pathway by p110-CAAX also failed to promote growth of the HEK-HT cells in soft agar (Fig. 4C). Thus, by two different criteria, we show that selective activation of either the Raf or PI3-kinase limbs of the Ras-signaling machinery does not promote the transformed phenotype of anchorage-independent growth in human epithelial cells.

\section{Raf and PI3-kinase pathways fail to cooperate to transform human cells}

Although we determined that activation of Raf or PI3kinase alone was not sufficient to promote the transformation of HEK-HT cells, perhaps the coordinate activation of both effector pathways is required to cause growth transformation. Evidence for this possibility is provided by the observation that PI3-kinase, activated by H-Ras12V40C, can cooperate with Raf activated by H-Ras12V35S to cause synergistic transformation of NIH 3 T3 cells (Khosravi-Far et al. 1996; Rodriguez-Vici- 
Hamad et al.

A

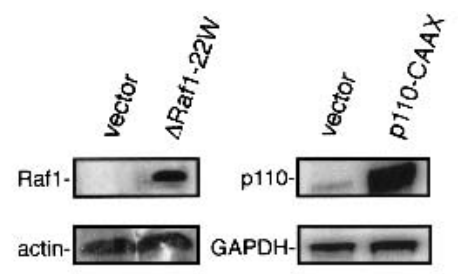

B

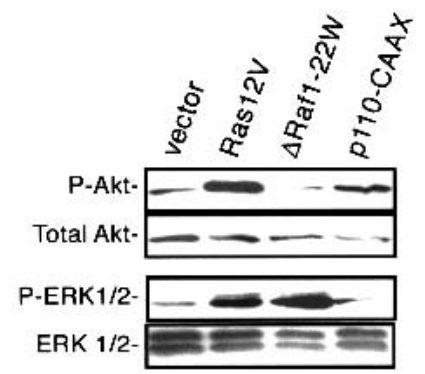

C

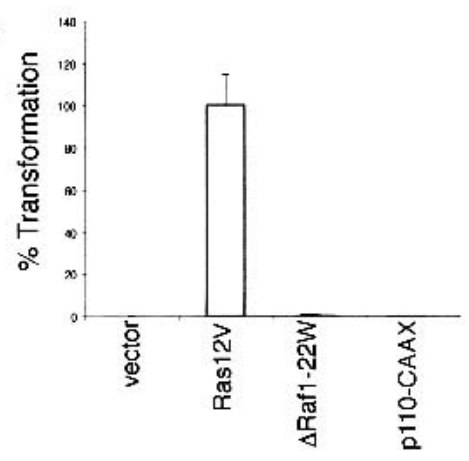

Figure 4. Specific activation of Raf or PI3-kinase is not sufficient to promote anchorage-independent growth of human cells. (A) Expression of $\Delta$ Raf1-22W or p110-CAAX was confirmed in the described HEK-HT cells by immunoblotting with an anti-Rafl antibody or by RT-PCR with primers specific for p110. Actin and GAPDH levels serve as loading controls. These cells also were infected with an empty vector. (B) Specific activation of either the MAP-kinase or PI3-kinase pathway by $\Delta$ Raf1-22W or p110-CAAX, respectively, was confirmed in the described HEK-HT by immunoblotting with antibodies specific for the phosphorylated forms of ERK1 and ERK2 or Akt. Total ERK $1 / 2$ and Akt levels serve as a loading control. (C) Anchorage-independent growth of HEK-HT cells expressing $\Delta$ Raf1$22 \mathrm{~W}$ or p110-CAAX, as calculated from the average number of colonies observed from three plates, and expressed as the percent of colonies observed in Ras $12 \mathrm{~V}$-transformed cells. A total of 50,000 HEK-HT cells expressing H-Ras12V seeded in soft agar yielded $311 \pm 46$ colonies.

ana et al. 1997). Therefore, we sought to determine whether the concomitant activation by effector mutants of both these effector pathways could, as has been observed in murine cells, transform human cells.

To test whether the combination of effector domain mutants Ras12V35S and Ras12V40C, which respectively stimulate Raf-1 and PI3-kinase, can promote transformation, we first confirmed that introduction of a second (null) vector had no effect on the transforming potential of any of the effector domain mutants in HEK-HT cells (Fig. 5A,B). Subsequently, HEK-HT cells stably express- ing H-Ras12V35S (Fig. 1A) were stably infected with a retrovirus encoding H-Ras12V40C. Because these effector mutants differ by only a single nucleotide, equivalent expression of both transgenes was verified by direct sequencing of cDNA derived from these cells (Fig. 5A). We then evaluated the cells for growth transformation using the soft agar assay. We found that the combined expression of Ras12V35S and Ras12V40C could only lead to an extremely low amount of anchorage-independent growth when compared with the Ras-transformed control cells (Fig. 5B). Thus, these effector domain mutants failed to cooperate and support the transformation of human cells. Moreover, HEK-HT cells stably infected with retroviruses encoding $\triangle \mathrm{Raf1}-22 \mathrm{~W}$ and p110-CAAX completely failed to grow in semi-solid medium (Fig. 5C). Thus, we conclude that stimulation of both the MAPkinase and PI3-kinase arms of oncogenic Ras together by two different approaches is insufficient to promote the transformed cell growth of HEK-HT cells.

\section{Raf and PI3-kinase enhance}

\section{Ras12V37G-induced transformation}

We found it surprising that the combined activation of both the PI3-kinase and the MAP-kinase pathways failed to transform the human cells, especially because the combination of these two pathways in murine cells is known to increase transformation above that observed with activation of either effector alone (Khosravi-Far et al. 1996; Rodriguez-Viciana et al. 1997). However, as Ras12V37G alone can transform human cells, albeit to a lesser extent than oncogenic Ras, we next determined whether the coactivation of Raf and PI3-kinase could cooperate with $37 \mathrm{G}$ and cause enhanced transforming activity. To directly test this hypothesis, we utilized Ras effector domain mutants or activated effector proteins to cause activation of PI3-kinase or Raf in cells coexpressing H-Ras12V37G.

The expression vector encoding H-Ras12V37G was stably introduced (Fig. 5A; data not shown) into HEKHT cells that had already been confirmed to express H-Ras12V35S (Fig. 1A) or $\Delta$ Raf1-22W (Fig. 4A). The resultant cells from both experiments were then assayed for anchorage-independent growth; we found that both now showed colony forming efficiencies that exceeded that seen with cells transformed by oncogenic H-Ras $12 \mathrm{~V}$ (Fig. 5B). Thus, activation of the MAP-kinase pathway by two independent approaches significantly enhanced the transforming potency of Ras12V37G in human cells.

Similarly, the expression vector encoding H-Ras12V37G was stably introduced (Fig. 5A; data not shown) into HEK-HT cells that expressed either H-Ras12V40C (Fig. 1A) or p110-CAAX (Fig. 4A), and the resultant cells were assayed for growth in semi-solid medium. Again, both methods to activate the PI3-kinase pathway potentiated the transformed growth of Ras12V37G expressing HEK-HT cells to levels greater than that observed in Ras12V-transformed control cells (Fig. 5B). Thus, consistent with the known roles of the MAP-kinase and PI3-kinase pathways in human cancer, 
A

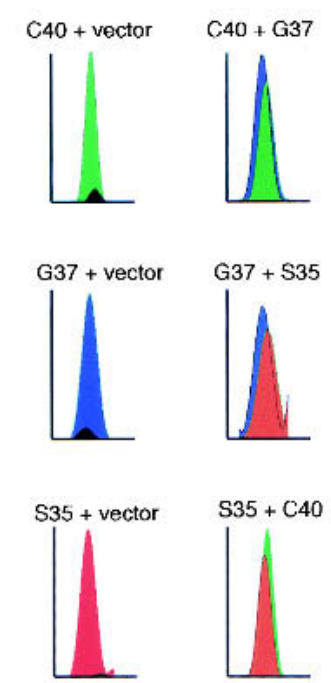

B

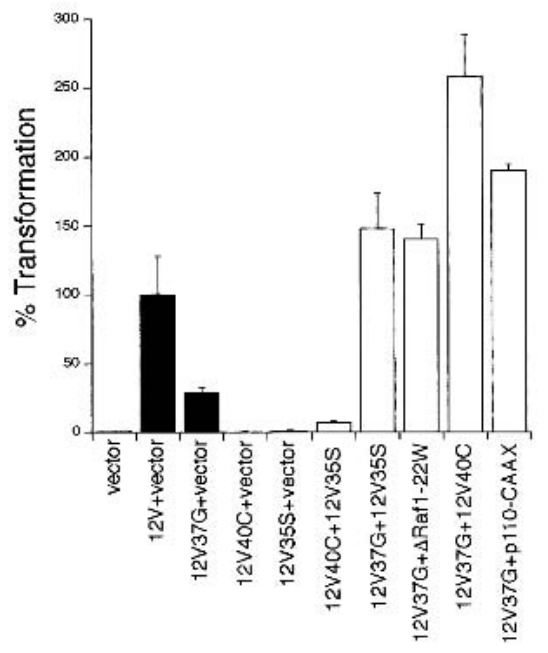

C

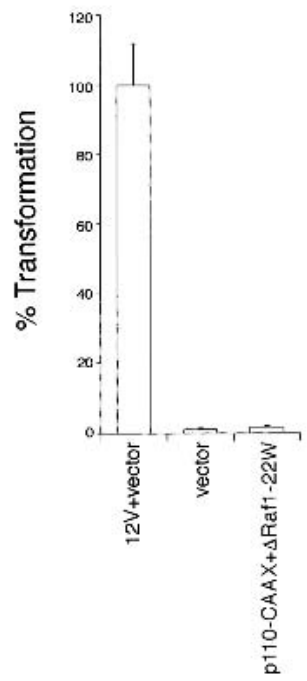

Figure 5. The MAP-kinase and PI3-kinase pathways together are not transforming, but greatly enhance Ras12V37G-mediated transformation. (A) Coexpression of Ras12V effector mutants was confirmed from direct sequencing of $\mathrm{H}$-Ras cDNA to identify the point mutations giving rise to 40C (green), 37G (blue), or 35S (red) effector mutations or the corresponding nucleotide of endogenous H-Ras (black in vector control) in the described double-infected HEK-HT cells. (B) Anchorage-independent growth of HEK-HT cells expressing the described combinations of Ras $12 \mathrm{~V}$ mutants with control vector (black bars) or the described effector mutants, $\Delta$ Raf1-22W or p110-CAAX (white bars), as calculated from the average number of colonies observed from three plates, and expressed as the percent of colonies observed in Ras $12 \mathrm{~V}+$ vector-transformed cells. A total of 50,000 Ras12V+vector-transformed HEK-HT yielded $295 \pm 83$ colonies in soft agar. $(C)$ Anchorage-independent growth of HEK-HT cells expressing Ras12V and control vector, vector alone, or $\Delta$ Raf1-22W and p110-CAAX, as calculated from the average number of colonies observed from three plates, and expressed as the percent of colonies observed in Ras12V+vector-transformed cells. A total of 50,000 Ras12V+vector-transformed HEK-HT yielded 463 \pm 55 colonies in soft agar.

activation of these pathways does enhance transformation in human cells. However, because anchorage-independent growth was not observed unless Ras12V37G was expressed, these results suggest that the effectorsignaling activity of $37 \mathrm{G}$ plays an essential role in Rasinduced transformation.

\section{The Ras12V37G effectors RalGEFs transform human cells}

Because Ras12V37G is critical for the Ras oncogenesis in human cells, we sought to identify the underlying signaling pathway responsible for transformation by this effector mutant. Although the transforming activity of Ras12V37G is generally ascribed to its ability to activate RalGEFs (Wolthuis and Bos 1999), this effector domain mutant does retain the ability to interact with other proteins (Khosravi-Far et al. 1996; Han et al. 1997; Linnemann et al. 1999; Cullen 2001). To test whether Ras12V37G transformation of HEK-HT cells involves the activation of RalGEF function, we first determined whether inhibition of RalGEF activity could impair Rastransforming activity. The S28N dominant-negative mutant of RalA forms a nonproductive complex with RalGEFs (Urano et al. 1996), impeding RalGEF activation of endogenous Ral small GTPases. We found that expression of RalA-28N in H-Ras12V-transformed HEK-
HT cells (Fig. 6A) did curb the ability of Ras-transformed cells to grow in soft agar (Fig. 6D) without decreasing Akt or ERK phosphorylation (Fig. 6B). Similarly, there was a growth reduction in Ras12V37G-expressing cells infected with the RalA-28N-expressing retrovirus (Fig. 6D). Thus, RalGEFs are necessary for Ras-mediated transformation.

Whereas RalA-28N attenuated Ras-induced transformation, it did not completely block it. Such a result could suggest the presence of other effectors downstream of Ras12V37G that could contribute to the oncogenic signal. Therefore, to directly test whether activation of RalGEFs alone is sufficient for transformation, we evaluated whether a constitutively activated RalGEF could cause the transformation of HEK-HT cells. As described above, there are four known RalGEF proteins that can interact with Ras (Wolthuis and Bos 1999; de Bruyn et al. 2000; Rebhun et al. 2000; Shao and Andres 2000), with the Ras-binding domain of Rlf having the highest affinity for GTP-Ras (Esser et al. 1998). Therefore, we established HEK-HT cells stably expressing Rlf-CAAX, a plasma membrane-targeted and constitutively activated version of Rlf (Wolthuis et al. 1997; Ramocki et al. 1998). We verified expression of this protein by immunoblot analysis (Fig. 6A), and, importantly, confirmed that RlfCAAX did not activate either ERK or Akt (Fig. 6B) but did activate Ral, as assessed by an increase in Ral-GTP 
Hamad et al.

Figure 6. RalGEFs are essential for Ras transformation of human cells. (A) RalA-28N and RlfCAAX expression was confirmed in HEK-HT or Ras12V-transformed HEK-HT cells, respectively, by immunoblotting with either an anti-Ral antibody (top) or an anti-HA antibody specific for the HA epitope cloned into Rlf (bottom). Actin levels serve as loading controls. (B) Phosphorylated Akt (P-AKT) or ERK 1 and 2 (P-ERK 1/2) levels were determined in the described cells by immunoblotting with antibodies specific for the phosphorylated forms of these proteins. The total amount of Akt, ERK 1/2 or actin detected by anti-Akt, ERK, or actin antibodies serve as loading controls. $(C)$ Ral-GTP levels were determined in the described cells by binding cellular Ral-GTP to the recombinant Ral-binding domain of the RalBP protein, followed by immunoblotting with a RalA-specific antibody. The total amount of Ral detected by the same anti-RalA antibody serve as loading controls. (D) Anchorage-independent growth of Ras $12 \mathrm{~V}$ or Ras12V37G-transformed HEK-HT cells in the absence (vector) or presence of RalA28N, or HEKHT cells in the absence (vector) or presence of RlfCAAX, as calculated from the average number of colonies observed from three plates, and expressed as the percent of colonies observed in Ras $12 \mathrm{~V}$ (black bars) or Ras12V37G (white bars) transformed cells. A total of 50,000 Ras12V-transformed HEK-HT cells yielded $295 \pm 83$ colonies in soft agar.

levels (Fig. 6C). The cells were next tested for anchorageindependent growth. Expression of Rlf-CAAX was sufficient to support the anchorage-independent growth of HEK-HT cells up to $60 \%$ of the level seen in the same cells transformed by Ras12V37G (Fig. 6D). Although it remains formally possible that this Rlf-CAAX-mediated transformation is unique to HEK cells, the observation that H-Ras12V37G transformed T-Ag and hTERT-expressing HEK cells, astrocytes and fibroblasts suggest that activation of a single RalGEF may be transforming in other human cell types. When taken together with the ability of the Ral dominant-negative to impair Ras $12 \mathrm{~V}$ transformation, these results suggest that oncogenic transformation of human cells by Ras12V37G is mediated, at least in part, by the activation of RalGEFs.

\section{Ras12V37G is essential for Ras-induced tumorigenesis of human cells}

Ras12V37G expression alone is sufficient to promote anchorage-independent growth of HEK cells. We next sought to determine whether signaling by this protein is required for the prior observations that primary human cells expressing hTERT and T-Ag require oncogenic Ras
B
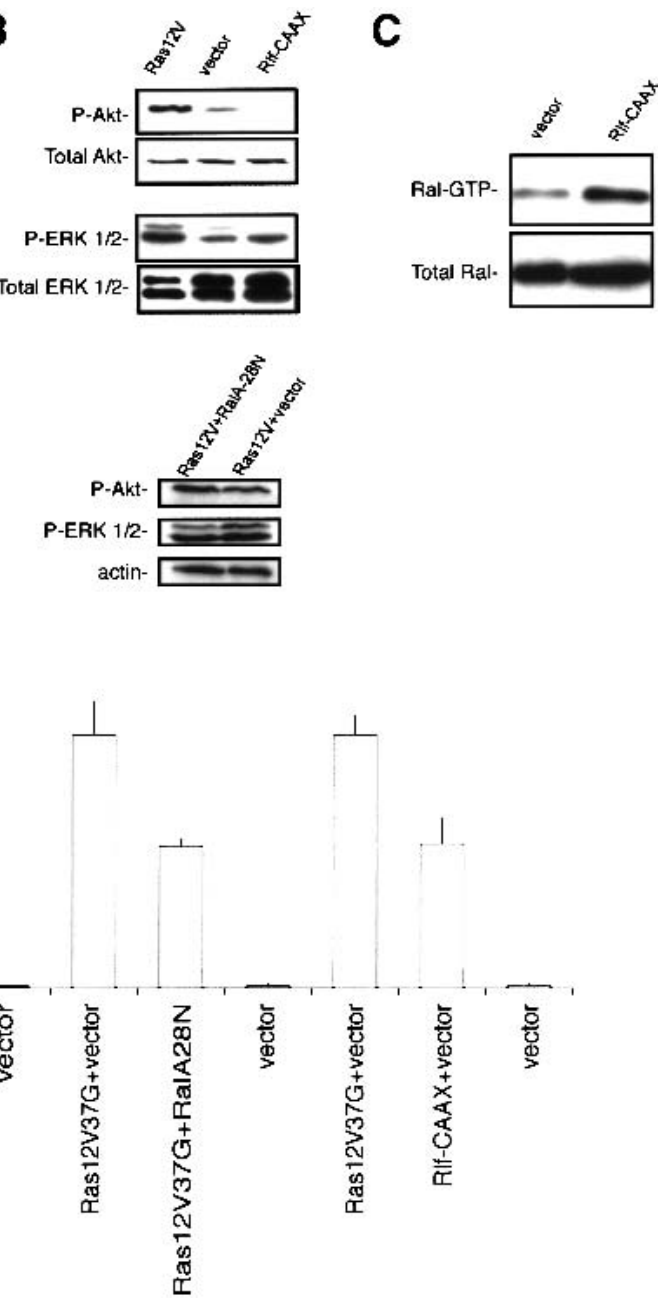

to form tumors when injected in immuno-compromised mice (Hahn et al. 1999). HEK-HT cells expressing H-Ras12V35S and H-Ras12V40C (Fig. 5A) were stably infected with either an empty vector control or an H-Ras12V37G-expressing construct. The resultant cells were then each injected into four immuno-compromised mice to assay for tumor growth. HEK-HT cells that coordinately expressed all three effector mutants readily formed tumors (Fig. 7) at a rate indistinguishable from that caused by oncogenic H-Ras12V (data not shown; Hahn et al. 1999). However, cells lacking Ras12V37G expression completely failed to form detectable masses in vivo, even after $\sim 50$ days, that is, twice as long as Ras12V37G-expressing cells required to form tumors (Fig. 7). Effectors of Ras12V37G are therefore necessary for Ras-dependent tumorigenesis in vivo. We next addressed whether Ras12V37G alone is sufficient for tumorigenic growth. In this case, HEK-HT cells expressing Ras12V37G failed to form tumors in vivo (data not shown). Such a result is consistent with our observations that Ras $12 \mathrm{~V} 37 \mathrm{G}$ is not as potent as Ras $12 \mathrm{~V}$ at promoting anchorage-independent growth (Fig. 1), and the known roles of the PI3-kinase and MAP-kinase pathways (Shields et al. 2000) in the more complex process of tu- 


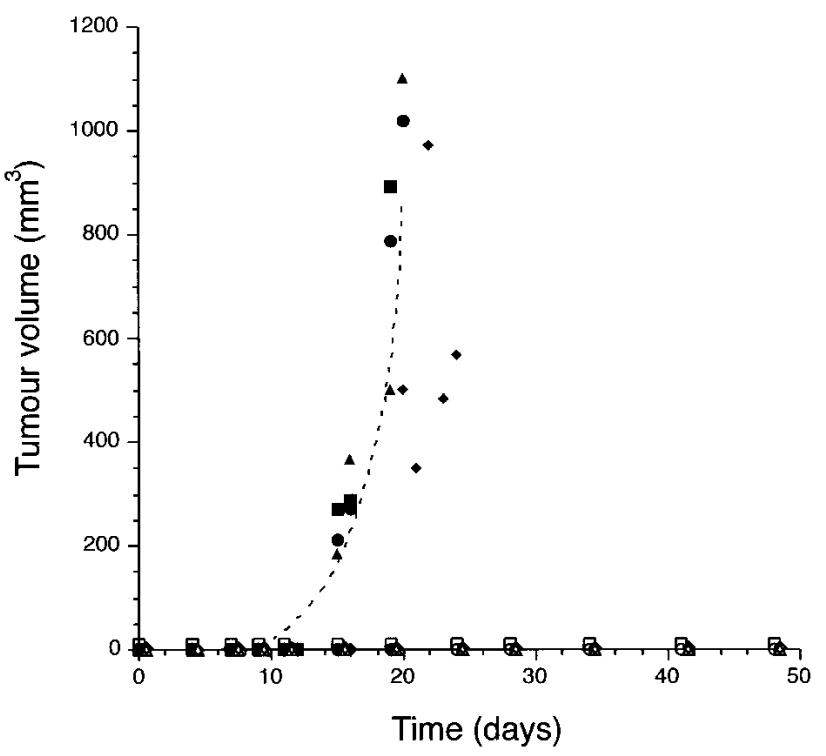

Figure 7 Ras12V37G is essential for tumor growth. Tumor volume $\left(\mathrm{mm}^{3}\right)$ of four mice injected with HEK-HT cells expressing $\mathrm{H}-\mathrm{Ras} 12 \mathrm{~V} 40 \mathrm{C}$ and H-Ras12V35S either in the absence (vector: $\bigcirc \square \Delta \diamond)$ or presence (OnA $\bullet$ ) of H-Ras12V37G, plotted against time (days).

morigenesis (Stanbridge and Wilkinson 1980). Thus, whereas effectors of H-Ras12V37G are not alone sufficient for tumorigenic growth they are, unlike in murine cells, essential for this process.

\section{Discussion}

Studies done primarily in NIH 3T3 and other rodent fibroblast model cell systems have established that the transforming activity of Ras is mediated largely by activating the Raf $>$ Mek>Erk signal cascade. In NIH 3T3 cells, activated mutants of Raf-1 (Bonner et al. 1985; Stanton et al. 1989; Leevers et al. 1994; Stokoe et al. 1994) or its target MEK (Alessi et al. 1994; Mansour et al. 1994) are completely sufficient to replace oncogenic Ras in the tumorigenic assays. This prompted earlier suggestions that Raf is the key effector of Ras transformation. Although studies of Ras transformation using other cell types now indicate that Raf-independent effector function also contributes to Ras transformation (Shields et al. 2000), Raf is still generally considered to form the backbone of Ras oncogenesis. The importance of this pathway in Ras transformation is reflected by the current evaluation of anti-Raf and anti-MEK strategies in preclinical and clinical studies (Monia et al. 1996; SeboltLeopold et al. 1999; Stevenson et al. 1999; Cunningham et al. 2000; Kloog and Cox 2000; Sebolt-Leopold 2000; Stein and Waterfield 2000). There is also strong evidence for an important supportive role for PI3-kinase in Ras transformation (Rodriguez-Viciana et al. 1997; Tolkacheva and Chan 2000). Aside from limited evidence for the importance of RalGEFs in Ras transformation, the role of other effectors in Ras transformation remains largely unresolved. In the present study, we determined unexpectedly that activation of the Raf and PI3-kinase effector pathways, either alone or together, was not sufficient to cause transformation of human cells. Instead, we found that activation of the RalGEF effector signaling alone, although found previously to not be sufficient to transform rodent fibroblasts, was sufficient to cause growth transformation of a variety of human cells. Moreover, because expression of an activated RalGEF did not lead to an increase in ERK or Akt phosphorylation, we rule out indirect activation of the MAP-kinase and PI3kinase pathways by RalGEFs as a mechanism accounting for the transforming capacity of RalGEFs. Whereas we did find that Raf and PI3-kinase could cooperate with H-Ras12V37G to promote transformation, our results suggest that it is the activation of effectors of this Ras mutant, such as RalGEFs, that is critical for Ras transformation in human cells, at least in this model system.

As such, we propose an effector-usage model, whereby multiple effectors of Ras contribute to the oncogenic signal, but that there exists significant differences between humans and mice in the relative potency of each pathway. Such species-specific differences in carcinogenesis are not restricted to Ras-related neoplasms. Transgenic mice lacking functional alleles of the tumor suppressors p53 (Donehower et al. 1992), Rb (Jacks et al. 1992), and NF-1 (Jacks et al. 1994), to name a few, also fail to give rise to the same types of tumors observed in familial human diseases harboring the same genetic changes (Cavenee et al. 1985; Legius et al. 1993; Colman et al. 1995; Kleihues et al. 1997). The recurrent discrepancies in the tumor phenotypes between humans and mice emphasize the value of dissecting oncogenesis in human cells.

We have shown that RalGEFs are transforming, supporting the premise that these proteins mediate, at least in part, Ras12V37G transformation. An interesting parallel to these findings is the observation that RalGEFs, and not other Ras effectors, are critical for proliferation of PC12 cells, although, in this case, RalGEFs oppose the growth-inhibitory action of Raf and PI3-kinase /Goi et al. 1999). With regards to the potency of RalGEFs for transformation, we note that whereas RalA-28N inhibited Ras-mediated transformation, it did not abolish it. Similarly, Rlf-CAAX promoted anchorage-independent growth, but not to the same level as Ras12V37G. It therefore remains possible that Ras12V37G may activate other effectors, in addition to RalGEFs, to promote the transformed phenotype. For example, H-Ras12V37G has been shown recently to retain the ability to bind and activate phospholipase $\mathrm{C} \varepsilon$ and stimulate production of two second messengers, inositol trisphosphate and diacylglycerol (Cullen 2001). These second messengers in turn promote an increase in intracellular calcium and activation of protein kinase $\mathrm{C}$, events that may contribute to growth transformation. Alternatively, the mutants utilized to implicate a RalGEF pathway may be only partially effective in mimicking the consequences of Ras activation of RalGEFs. For example, at least four distinct RalGEFs have been identified as Ras effectors, and, hence, expression of only one activated form may 
not be sufficient. Consistent with this possibility, we found that coexpression of two constitutively activated RalGEF members caused a more robust transformation than one alone (data not shown).

The observation that Ras12V37G was required for tumorigenic growth supports the notion that RalGEFs are important for tumorigenesis. Because RalGEFs are bona fide effectors of Ras (Wolthuis and Bos 1999), and Ras is commonly activated in human cancers, either through an activating mutation (Bos 1989) or by inappropriate activation of growth factor receptors (Shields et al. 2000), it stands to reason that the RalGEF pathway is activated in at least some human cancers. We also point out that a RalGEF has been identified that is oncogenic (D'Adamo et al. 1997), opening up the possibility that this pathway could even be activated selectively during tumorigenesis. We can, however, only speculate on the mechanism whereby RalGEFs transform human cells. The only known substrates for these proteins are the monomeric G-proteins RalA and RalB. RalGEFs bind to the GDPbound state of Ral and facilitate the exchange of GDP for GTP, thereby activating these proteins (Wolthuis and Bos 1999; de Bruyn et al. 2000; Rebhun et al. 2000; Shao and Andres 2000). However, no oncogenic potential has been shown for activated Ral proteins alone, although activated Ral can modestly potentiate the transforming activity of activated Raf in rodent fibroblast transformation assays (Urano et al. 1996; White et al. 1996). Consistent with these data, an activated form of Ral failed to promote significant growth of the human cells in soft agar (data not shown). Thus, it is possible that activation mutations in Ral may not recapitulate the activation by Rlf-CAAX or H-Ras. Alternatively, Rlf-CAAX may activate other signaling proteins, either because they are natural substrates or by virtue of Rlf-CAAX overexpression or constitutive membrane targeting. Future studies will be needed to determine how RalGEFs transform human cells and whether RalGEFs are up-regulated in human tumors that harbor mutated Ras.

In murine cells, the MAP-kinase pathway is clearly critical for tumorigenesis and is also commonly activated in human tumors (Hoshino et al. 1999). Consequently, this pathway has been the target of aggressive efforts to develop inhibitors to treat human cancers. A variety of pharmacologic and antisense approaches have been developed to block the activities of Raf and MEK and are now under clinical evaluation (Stevenson et al. 1999; Cunningham et al. 2000; Kloog and Cox 2000; Sebolt-Leopold 2000). Similarly, PI3-kinase has been implicated in human cancer, particularly for its role in cell survival and proliferation. In certain cancer types, the PI3-kinase gene is amplified, the protein overexpressed (Phillips et al. 1998; Ma et al. 2000) or expression of the PTEN gene, a negative regulator of the PI3-kinase pathway, is lost (Cantley and Neel 1999). Targeted inhibition of specific PI3-kinases has also been proposed as an avenue of cancer treatment (Stein and Waterfield 2000). Given that inhibition of these Ras effectors has profound effects on tumor growth and that Ras12V37G was found to be essential for transformation of human cells, we speculate that inhibition of effectors of Ras12V37G, such as RalGEFs, may also hold promise as a cancer treatment strategy.

In summary, there is considerable debate regarding the accuracy of mouse models for human cancer. In this study of both human and murine cells, we now show that the signaling pathway engaged by H-Ras12V37G is sufficient for Ras-dependant transformation and necessary for tumor formation in human cells, and that RalGEFs, known targets of this effector mutant, are critical components of this process. A surprising observation from our analyses was that the two most critical effectors of Ras transformation of rodent fibroblasts were not sufficient, either alone, or in combination to cause transformation of the human cells. These observations highlight the value of dissecting the signaling pathways of oncoproteins in human cells and suggest that the effectors of H-Ras12V37G, such as RalGEF, could represent potential targets for the development of anti-Ras drugs for the treatment of human cancers.

\section{Materials and methods}

\section{Cell lines}

Retrovirus constructs were created by subcloning FLAG-H-Ras and FLAG-H-Ras12V (an amino-terminal FLAG tag was inserted in frame into $\mathrm{H}$-Ras or $\mathrm{H}-\mathrm{Ras} 12 \mathrm{~V}$ by $\mathrm{PCR}$ ) in the absence or presence of effector domain mutants S35, C40 or G37 (White et al. 1995; Rodriguez-Viciana et al. 1997) generated by sitedirected mutagenesis, RalA- $28 \mathrm{~N}$ [the $28 \mathrm{~N}$ mutation (Urano et al. 1996) was introduced by site-directed mutagenesis into RalA (Frech et al. 1990), a kind gift of R.A. Weinberg (Massachusetts Institute of Technology, Cambridge, MA)], HA-Rlf-CAAX (Wolthuis et al. 1997), p110 $\alpha$-CAAX (Rodriguez-Viciana et al. 1997), $\Delta$ Raf1-22W (Stanton et al. 1989), and T-Ag [generated by PCR amplifying the early region of SV40 of plasmid pSVneo (Southern and Berg 1982) with primers that incorporate BamHI and EcoRI sites] into pBabe vectors (Morgenstern and Land 1990) creating the following plasmids pBabepuro: FLAG-HRas, FLAG-H-Ras12V (and 35S, 37G, or 40C), HA-Rlf-CAAX, p110 $\alpha$-CAAX, and $\Delta$ Raf1-22W; pBabebleo: FLAG-H-Ras12V (and 35S or C40), RalA-28N; and pBabeneo: T/t-Ag. FLAG-HRas12V35S was also cloned into the vector pWZL-Blast [a kind gift of J.P. Morgenstern (Millennium Pharmaceuticals Inc., Cambridge, MA)].

At the earliest passage, the appropriate derived amphotrophic retroviruses encoding $\mathrm{H}$-Ras or effector mutants thereof or Ras effectors were used to infect T-Ag + hTERT expressing primary HEK (Armbruster et al. 2001), human astrocyte (Rich et al. 2001), human BJ fibroblasts (Hahn et al. 1999), or primary murine fibroblasts from two independent strains of C57/Bl6; 129Sv mice stably infected with pBabeneoT/t-Ag [a kind gift of X.-F. Wang and A.M. Pendergast (Duke University Medical Center, Durham, NC)] or NIH 3T3 (Khosravi-Far et al. 1996) cells, similar to approaches described previously (Hahn et al. 1999; Rich et al. 2001). Stable polyclonal populations resistant to the appropriate drug selection markers were assayed for anchorage-independent growth by the third confluent plate. The same procedure was followed to add additional transgenes.

\section{Immunoblotting}

Exponentially growing cells from the described cell lines were lysed, protein concentrations were measured by Lowry assay 
(Bio-Rad), and $30 \mu \mathrm{g}$ of soluble lysate separated by SDS-PAGE and immunoblotted similar to methods described previously (Armbruster et al. 2001) by use of the M2 anti-FLAG (Sigma), anti-RalA (Signal Transduction Laboratories), E-10 anti-Raf1, C-2 or I-19 anti-actin (Santa Cruz Biotechnology), or 12CA5 anti-HA (Roche) antibodies to detect FLAG-H-Ras, RalA28N, $\Delta$ Raf1-22W, actin, and HA-Rlf-CAAX. To monitor activation of the MAP-kinase and PI3-kinase pathways, the described cell lines were serum starved in medium supplemented with $0.5 \%$ fetal bovine serum for $48 \mathrm{~h}$, lysed, resolved by SDS-PAGE, and immunoblotted similar to that described above. The K-23 antiERK1/2 (Santa Cruz), E10 anti-phospho(Thr 202/Tyr 204)-p42/ 44 MAPK, anti-Akt (Cell Signaling Technology), and S472 antiphospho(Ser 473)-Akt (New England Biolabs) antibodies were used to detect ERK 1 and ERK 2, phosphorylated ERK 1 and ERK 2, Akt, and phosphorylated Akt, respectively.

\section{Ral-GTP assay}

Levels of endogenous Ral-GTP were assayed as described previously (Murphy et al. 2002) by incubating cell lysates with glutathione-agarose bound recombinant GST-RalDB (produced and purified from bacteria), which adheres specifically to Ral in the GTP-bound state. Beads were washed and bound proteins resolved by SDS-PAGE and Ral detected by immunoblotting with the aforementioned anti-RalA antibody. Total Ral levels were determined by immunoblotting lysates with the same antibody.

\section{$R T-P C R$}

Total RNA was isolated and RT-PCR amplified using methodologies described previously (Hahn et al. 1999; Rich et al. 2001) with primers specific for H-Ras (5'-ACGACGATGACAAGA CGGAA-3' and 5'-ATGGCGCTGTACTCCTCCT-3'), p1 10 (5' GACAATGTGAACACTCAAAGAG-3'; and 5'-CACCAATAG GGTTCAG CAGA-3') and GAPDH (Hahn et al. 1999). To identify specific effector mutants, H-Ras RT-PCR amplified products were sequenced to determine the nucleotide at positions $+105,+111$, and +121 (corresponding to the 35 S, G37, and 40C mutations, respectively).

\section{Soft agar}

Cells were suspended in soft agar and colonies $>30$ cells scored after 3 wk, as described previously (Cifone and Fidler 1980). Assays were done in triplicate, and in most cases independently, at least twice.

\section{Tumors}

Under a protocol approved by the Duke University Institutional Animal Care and Use Committee, $2 \times 10^{6}$ cells were injected subcutaneously into the flanks of four SCID/Beige mice, after which tumor volumes were determined at regular intervals, as described previously (Hahn et al. 1999; Gou et al. 2001).

\section{Acknowledgments}

We thank Pat Casey, Tony Means, Ann Marie Pendergast, XiaoFan Wang, Bob Weinberg, Tso-Pang Yao, and members of the Counter laboratory for helpful discussions or review of the manuscript. This work was supported in part by grants from the V-Foundation (C.M.C.), the Pediatric Brain Tumor Foundation (J.N.R.), and the NIH, administered through the NCI (CA82481 and CA094184 to C.M.C., CA69577 to C.J.D., and NS02055 to J.N.R.), and scholarships to C.M.C. by the Sidney Kimmel Foun- dation for Cancer Research, A.E.K. from the Susan G. Komen Breast Cancer Foundation, and J.H.E. from the Terry and Frances Seelinger Foundation.

The publication costs of this article were defrayed in part by payment of page charges. This article must therefore be hereby marked "advertisement" in accordance with 18 USC section 1734 solely to indicate this fact.

\section{References}

Alessi, D.R., Saito, Y., Campbell, D.G., Cohen, P., Sithanandam, G., Rapp, U., Ashworth, A., Marshall, C.J., and Cowley, S. 1994. Identification of the sites in MAP kinase kinase-1 phosphorylated by p74raf-1. EMBO I. 13: 1610-1619.

Armbruster, B.N., Banik, S.S., Guo, C., Smith, A.C., and Counter, C.M. 2001. N-terminal domains of the human telomerase catalytic subunit required for enzyme activity in vivo. Mol. Cell. Biol. 21: 7775-7786.

Bergsagel, D.J., Finegold, M.J., Butel, J.S., Kupsky, W.J., and Garcea., R.L. 1992. DNA sequences similar to those of simian virus 40 in ependymomas and choroid plexus tumors of childhood. N. Engl. J. Med. 326: 988-993.

Bodnar, A.G., Ouellette, M., Frolkis, M., Holt, S.E., Chiu, C.P., Morin, G.B., Harley, C.B., Shay, J.W., Lichtsteiner, S., and Wright, W.E. 1998. Extension of life-span by introduction of telomerase into normal human cells. Science 279: 349-352.

Bonner, T.I., Kerby, S.B., Sutrave, P., Gunnell, M.A., Mark, G., and Rapp, U.R. 1985. Structure and biological activity of human homologs of the raf/mil oncogene. Mol. Cell. Biol. 5: 1400-1407.

Bos, J.L. 1989. ras oncogenes in human cancer: A review. Cancer Res. 49: 4682-4689.

Cantley, L.C. and Neel, B.G. 1999. New insights into tumor suppression: PTEN suppresses tumor formation by restraining the phosphoinositide 3-kinase/AKT pathway. Proc. Natl. Acad. Sci. 96: 4240-4245.

Carbone, M., Pass, H.I., Rizzo, P., Marinetti, M., Di Muzio, M., Mew, D.J., Levine, A.S., and Procopio, A. 1994. Simian virus 40-like DNA sequences in human pleural mesothelioma. Oncogene 9: 1781-1790.

Cavenee, M.F., Hansen, W.K., Nordenskjold, M., Kock, E., Maumenee, I., Squire, J.A., Phillips, R.A., and Gallie, B.L. 1985. Genetic origin of mutations predisposing to retinoblastoma. Science 228: 501-503.

Chadeneau, C., Siegel, P., Harley, C.B., Muller, W.J., and Bacchetti, S. 1995. Telomerase activity in normal and malignant murine tissues. Oncogene 11: 893-898.

Cifone, M.A. and Fidler, I.J. 1980. Correlation of patterns of anchorage-independent growth with in vivo behavior of cells from a murine fibrosarcoma. Proc. Nat1. Acad. Sci. 77: 1039-1043.

Colman, S.D., Williams, C.A., and Wallace, M.R. 1995. Benign neurofibromas in type 1 neurofibromatosis (NF1) show somatic deletions of the NF1 gene. Nat. Genet. 11:90-92.

Counter, C.M., Hahn, W.C., Wei, W., Caddle, S.D., Beijersbergen, R.L., Lansdorp, P.M., Sedivy, J.M., and Weinberg, R.A. 1998. Dissociation among in vitro telomerase activity, telomere maintenance, and cellular immortalization. Proc. Natl. Acad. Sci. 95: 14723-14728.

Cowley, S., Paterson, H., Kemp, P., and Marshall, C.J. 1994. Activation of MAP kinase kinase is necessary and sufficient for PC12 differentiation and for transformation of NIH 3T3 cells. Cell 77: 841-852.

Cullen, P.J. 2001. Ras effectors: Buying shares in Ras plc. Curr. Biol. 11: R342-R344.

Cunningham, C.C., Holmlund, J.T., Schiller, J.H., Geary, R.S., Kwoh, T.J., Dorr, A., and Nemunaitis, J. 2000. A phase I trial 
of c-Raf kinase antisense oligonucleotide ISIS 5132 administered as a continuous intravenous infusion in patients with advanced cancer. Clin. Cancer Res. 6: 1626-1631.

D'Adamo, D.R., Novick, S., Kahn, J.M., Leonardi, P., and Pellicer, A. 1997. rsc: A novel oncogene with structural and functional homology with the gene family of exchange factors for Ral. Oncogene 14: 1295-1305.

de Bruyn, K.M., de Rooij, J., Wolthuis, R.M., Rehmann, H., Wesenbeek, J., Cool, R.H., Wittinghofer, A.H., and Bos, J.L. 2000. RalGEF2, a pleckstrin homology domain containing guanine nucleotide exchange factor for Ral. J. Biol. Chem. 275: 29761-29766.

Donehower, L.A., Harvey, M., Slagle, B.L., McArthur, M.J., Montgomery, Jr., C.A., Butel, J.S., and Bradley, A. 1992. Mice deficient for p53 are developmentally normal but susceptible to spontaneous tumors. Nature 356: 215-221.

Elenbaas, B., Spirio, L., Koerner, F., Fleming, M.D., Zimonjic, D.B., Donaher, J.L., Popescu, N.C,. Hahn, W.C., and Weinberg, R.A. 2001. Human breast cancer cells generated by oncogenic transformation of primary mammary epithelial cells. Genes \& Dev. 15: 50-65.

Esser, D., Bauer, B., Wolthuis, R.M., Wittinghofer, A., Cool, R.H., and Bayer, P. 1998. Structure determination of the Rasbinding domain of the Ral-specific guanine nucleotide exchange factor Rlf. Biochemistry 37: 13453-13462.

Frech, M., Schlichting, I., Wittinghofer, A., and Chardin, P. 1990. Guanine nucleotide binding properties of the mammalian RalA protein produced in Escherichia coli. I. Biol. Chem. 265: 6353-6359.

Goi, T., Rusanescu, G., Urano, T., and Feig, L.A. 1999. Ralspecific guanine nucleotide exchange factor activity opposes other Ras effectors in PC12 cells by inhibiting neurite outgrowth. Mol. Cell. Biol. 19: 1731-1741.

Gou, C., Geverd, D., Liao, R., Hamad, N., Counter, C.M., and Price, D.T. 2001. Inhibition of telomerase is related to the lifespan and tumorigenicity of human prostate cancer cells. J. Urol. 166: 694-698.

Greenberg, R.A., Allsopp, R.C., Chin, L., Morin, G.B., and DePinho, R.A. 1998. Expression of mouse telomerase reverse transcriptase during development, differentiation and proliferation. Oncogene 16: 1723-1730.

Hahn, W.C., Counter, C.M., Lundberg, A.S., Beijersbergen, R.L., Brooks, M.W., and Weinberg, R.A. 1999. Creation of human tumor cells with defined genetic elements. Nature 400: 464-468.

Hahn, W.C., Dessain, S.K., Brooks, M.W., King, J.E., Elenbaas, B., Sabatini, D.M., DeCaprio, J.A., and Weinberg, R.A. 2002. Enumeration of the simian virus 40 early region elements necessary for human cell transformation. Mol. Cell. Biol. 22: 2111-2123.

Han, L., Wong, D., Dhaka, A., Afar, D., White, M., Xie, W., Herschman, H., Witte, O., and Colicelli, J. 1997. Protein binding and signaling properties of RIN1 suggest a unique effector function. Proc. Natl. Acad. Sci. 94: 4954-4959.

Hoshino, R., Chatani, Y., Yamori, T., Tsuruo, T., Oka, H., Yoshida, O., Shimada, Y., Ari-i, S., Wada, H., Fujimoto, J., et al. 1999. Constitutive activation of the 41-/43-kDa mitogenactivated protein kinase signaling pathway in human tumors. Oncogene 18: 813-822.

Jacks, T., Fazeli, A., Schmitt, E.M., Bronson, R.T., Goodell, M.A., and Weinberg, R.A. 1992. Effects of an Rb mutation in the mouse. Nature 359: 295-300.

Jacks, T., Shih, T.S., Schmitt, E.M., Bronson, R.T., Bernards, A., and Weinberg, R.A. 1994. Tumor predisposition in mice heterozygous for a targeted mutation in Nf1. Nat. Genet. 7: 353-361.

Johnson, L., Mercer, K., Greenbaum, D., Bronson, R.T., Crowley, D., Tuveson, D.A., and Jacks, T. 2001. Somatic activation of the K-ras oncogene causes early onset lung cancer in mice. Nature 410: 1111-1116.

Khosravi-Far, R., Solski, P.A., Clark, G.J., Kinch, M.S., and Der, C.J. 1995. Activation of Rac1, RhoA, and mitogen-activated protein kinases is required for Ras transformation. Mol. Cell. Biol. 15: 6443-6453.

Khosravi-Far, R., White, M.A., Westwick, J.K., Solski, P.A., Chrzanowska-Wodnicka, M., Van Aelst, L., Wigler, M.H., and Der, C.J. 1996. Oncogenic Ras activation of Raf/mitogen-activated protein kinase-independent pathways is sufficient to cause tumorigenic transformation. Mol. Cell. Biol. 16: 3923-3933.

Kleihues, P., Schauble, B., zur Hausen, A., Esteve, J., and Ohgaki, H. 1997. Tumors associated with p53 germline mutations: A synopsis of 91 families. Am. J. Pathol. 150: 1-13.

Kloog, Y. and Cox, A.D. 2000. RAS inhibitors: Potential for cancer therapeutics. Mol. Med. Today 6: 398-402.

Kolch, W., Heidecker, G., Lloyd, P., and Rapp, U.R. 1991. Raf-1 protein kinase is required for growth of induced NIH/3T3 cells. Nature 349: 426-428.

Kyriakis, J.M., App, H., Zhang, X.F., Banerjee, P., Brautigan, D.L., Rapp, U.R., and Avruch, J. 1992. Raf-1 activates MAP kinase-kinase. Nature 358: 417-421.

Lednicky, J.A., Garcea, R.L., Bergsagel, D.J., and Butel, J.S. 1995 Natural simian virus 40 strains are present in human choroid plexus and ependymoma tumors. Virology 212: 710-717.

Leevers, S.J., Paterson, H.F., and Marshall, C.J. 1994. Requirement for Ras in Raf activation is overcome by targeting Raf to the plasma membrane. Nature 369: 411-414.

Legius, E., Marchuk, D.A., Collins, F.S., and Glover, T.W. 1993. Somatic deletion of the neurofibromatosis type 1 gene in a neurofibrosarcoma supports a tumor suppressor gene hypothesis. Nat. Genet. 3: 122-126.

Linnemann, T., Geyer, M., Jaitner, B.K., Block, C., Kalbitzer, H.R., Wittinghofer, A., and Herrmann, C. 1999. Thermodynamic and kinetic characterization of the interaction between the Ras binding domain of AF6 and members of the Ras subfamily. J. Biol. Chem. 274: 13556-13562.

Livingston, D.M. 1992. Functional analysis of the retinoblastoma gene product and of RB-SV40 T antigen complexes. Cancer Surv. 12: 153-160.

Lu, Z., Hornia, A., Joseph, T., Sukezane, T., Frankel, P., Zhong, M., Bychenok, S., Xu, L., Feig, L.A., and Foster, D.A. 2000. Phospholipase D and RalA cooperate with the epidermal growth factor receptor to transform $3 \mathrm{Y} 1$ rat fibroblasts. Mol. Cell. Biol. 20: 462-467.

Ludlow, J.W. 1993. Interactions between SV40 large-tumor antigen and the growth suppressor proteins pRB and p53. FASEB J. 7: 866-871.

Ma, Y.Y., Wei, S.J., Lin, Y.C., Lung, J.C., Chang, T.C., WhangPeng, J., Liu, J.M., Yang, D.M., Yang, W.K., and Shen, C.Y. 2000. PIK3CA as an oncogene in cervical cancer. Oncogene 19: $2739-2744$.

Mansour, S.J., Matten, W.T., Hermann, A.S., Candia, J.M., Rong, S., Fukasawa, K., Vande Woude, G.F., and Ahn, N.G. 1994. Transformation of mammalian cells by constitutively active MAP kinase kinase. Science 265: 966-970.

Martini, F., Iaccheri, L., Lazzarin, L., Carinci, P., Corallini, A., Gerosa, M., Iuzzolino, P., Barbanti-Brodano, G., and Tognon, M. 1996. SV40 early region and large $\mathrm{T}$ antigen in human brain tumors, peripheral blood cells, and sperm fluids from healthy individuals. Cancer Res. 56: 4820-4825.

Miyamoto, S., Sukumar, S., Guzman, R.C., Osborn, R.C., and Nandi, S. 1990. Transforming c-Ki-ras mutation is a preneoplastic event in mouse mammary carcinogenesis induced in vitro by N-methyl-N-nitrosourea. Mol. Cell. Biol. 10: 1593-1599.

Monia, B.P., Johnston, J.F., Geiger, T., Muller, M., and Fabbro, D. 1996. Antitumor activity of a phosphorothioate antisense 
oligodeoxynucleotide targeted against C-raf kinase. Nat. Med. 2: 668-675.

Morgenstern, J.P. and Land, H. 1990. Advanced mammalian gene transfer: High titre retroviral vectors with multiple drug selection markers and a complementary helper-free packaging cell line. Nucleic Acids Res. 18: 3587-3596.

Murphy, G.A., Graham, S.M., Morita, S., Reks, S.E., RogersGraham, K., Voitek, A., Kelley, G.G., and Der, C.J. 2002. Involvement of phosphatidylinositol 3-kinase, but not RalGDS, in TC21/R- Ras2-mediated transformation. J. Biol. Chem. 277: 9966-9975.

Nakamura, T.M. and Cech, T.R. 1998. Reversing time: origin of telomerase. Cell 92: 587-590.

Oldham, S.M., Clark, G.J., Gangarosa, L.M., Coffey, Jr., R.J., and Der, C.J. 1996. Activation of the Raf-1/MAP kinase cascade is not sufficient for Ras transformation of RIE-1 epithelial cells. Proc. Natl. Acad. Sci. 93: 6924-6928.

Pallas, D.C., Shahrik, L.K., Martin, B.L., Jaspers, S., Miller, T.B., Brautigan, D.L., and Roberts, T.M. 1990. Polyoma small and middle $\mathrm{T}$ antigens and SV40 small $\mathrm{t}$ antigen form stable complexes with protein phosphatase 2A. Cell 60: 167-176.

Phillips, W.A., St. Clair, F., Munday, A.D., Thomas, R.J., and Mitchell, C.A. 1998. Increased levels of phosphatidylinositol 3-kinase activity in colorectal tumors. Cancer 83: 41-47.

Qiu, R.G., Chen, J., Kirn, D., McCormick, F., and Symons, M. 1995. An essential role for Rac in Ras transformation. $\mathrm{Na}$ ture 374: 457-459.

Ramocki, M.B., White, M.A., Konieczny, S.F., and Taparowsky, E.J. 1998. A role for RalGDS and a novel Ras effector in the Ras-mediated inhibition of skeletal myogenesis. I. Biol. Chem. 273: 17696-17701.

Rebhun, J.F., Chen, H., and Quilliam, L.A. 2000. Identification and characterization of a new family of guanine nucleotide exchange factors for the ras-related GTPase Ral. J. Biol. Chem. 275: 13406-13410.

Rich, J.N., Guo, C., McLendon, R.E., Bigner, D.D., Wang, X.F., and Counter, C.M. 2001. A genetically tractable model of human glioma formation. Cancer Res. 61: 3556-3560.

Rodriguez-Viciana, P., Warne, P.H., Vanhaesebroeck, B., Waterfield, M.D., and Downward, J. 1996. Activation of phosphoinositide 3-kinase by interaction with Ras and by point mutation. EMBO J. 15: 2442-2451.

Rodriguez-Viciana, P., Warne, P.H., Khwaja, A., Marte, B.M., Pappin, D., Das, P., Waterfield, M.D., Ridley, A., and Downward, J. 1997. Role of phosphoinositide 3-OH kinase in cell transformation and control of the actin cytoskeleton by Ras. Cell 89: 457-467.

Rubin, H., Figge, J., Bladon, M.T., Chen, L.B., Ellman, M., Bikel, I., Farrell, M., and Livingston, D.M. 1982. Role of small t antigen in the acute transforming activity of SV40. Cell 30: 469-480.

Schaap, D., van der Wal, J., Howe, L.R., Marshall, C.J., and van Blitterswijk, W.J. 1993. A dominant-negative mutant of raf blocks mitogen-activated protein kinase activation by growth factors and oncogenic p21ras. I. Biol. Chem. 268: 20232-20236.

Sebolt-Leopold, J.S. 2000. Development of anticancer drugs targeting the MAP kinase pathway. Oncogene 19: 6594-6599.

Sebolt-Leopold, J.S., Dudley, D.T., Herrera, R., Van Becelaere, K., Wiland, A., Gowan, R.C., Tecle, H., Barrett, S.D., Bridges, A., Przybranowski, S., et al. 1999. Blockade of the MAP kinase pathway suppresses growth of colon tumors in vivo. Nat. Med. 5: 810-816.

Serrano, M., Lin, A.W., McCurrach, M.E., Beach, D., and Lowe, S.W. 1997. Oncogenic ras provokes premature cell senescence associated with accumulation of p53 and p16INK4a. Cell 88: 593-602.
Shao, H. and Andres, D.A. 2000. A novel RalGEF-like protein, RGL3, as a candidate effector for rit and Ras. J. Biol. Chem. 275: 26914-26924.

Shay, J.W. and Bacchetti, S. 1997. A survey of telomerase activity in human cancer. Eur. J. Cancer 33: 787-791.

Shields, J.M., Pruitt, K., McFall, A., Shaub, A., and Der, C.J. 2000. Understanding Ras: 'it ain't over 'til it's over'. Trends Cell Biol. 10: 147-154.

Sleigh, M.J., Topp, W.C., Hanich, R., and Sambrook, J.F. 1978. Mutants of SV40 with an altered small t protein are reduced in their ability to transform cells. Cell 14: 79-88.

Southern, P.J. and Berg, P. 1982. Transformation of mammalian cells to antibiotic resistance with a bacterial gene under control of the SV40 early region promoter. J. Mol. Appl. Genet. 1: 327-341.

Stanbridge, E.J. and Wilkinson, J. 1980. Dissociation of anchorage independence from tumorigenicity in human cell hybrids. Int. J. Cancer 26: 1-8.

Stanton, V.P., Nichols, D.W., Laudano, A.P., and Cooper, G.M. 1989. Definition of the human raf amino-terminal regulatory region by deletion mutagenesis. Mol. Cell. Biol. 9: 639-647.

Stein, R.C. and Waterfield, M.D. 2000. PI3-kinase inhibition: A target for drug development? Mol. Med. Today 6: 347-357.

Stevenson, J.P., Yao, K.S., Gallagher, M., Friedland, D., Mitchell, E.P., Cassella, A., Monia, B., Kwoh, T.J., Yu, R., Holmlund, J., et al. 1999. Phase I clinical/pharmacokinetic and pharmacodynamic trial of the c-raf- 1 antisense oligonucleotide ISIS 5132 (CGP 69846A). J. Clin. Oncol. 17: 2227-2236.

Stokoe, D., Macdonald, S.G., Cadwallader, K., Symons, M., and Hancock, J.F. 1994. Activation of Raf as a result of recruitment to the plasma membrane. Science 264: 1463-1467.

Tolkacheva, T. and Chan, A.M. 2000. Inhibition of H-Ras transformation by the PTEN/MMAC1/TEP1 tumor suppressor gene. Oncogene 19: 680-689.

Urano, T., Emkey, R., and Feig, L.A. 1996. Ral-GTPases mediate a distinct downstream signaling pathway from Ras that facilitates cellular transformation. EMBO J. 15: 810-816.

Vaziri, H. and Benchimol, S. 1998. Reconstitution of telomerase activity in normal human cells leads to elongation of telomeres and extended replicative life span. Curr. Biol. 8: 279-282.

Ward, Y., Wang, W., Woodhouse, E., Linnoila, I., Liotta, L., and Kelly, K. 2001. Signal pathways which promote invasion and metastasis: Critical and distinct contributions of extracellular signal-regulated kinase and Ral-specific guanine exchange factor pathways. Mol. Cell. Biol. 21: 5958-5969.

Westwick, J.K., Cox, A.D., Der, C.J., Cobb, M.H., Hibi, M., Karin, M., and Brenner, D.A. 1994. Oncogenic Ras activates c-Jun via a separate pathway from the activation of extracellular signalregulated kinases. Proc. Nat1. Acad. Sci. 91: 6030-6034.

White, M.A., Nicolette, C., Minden, A., Polverino, A., Van Aelst, L., Karin, M., and Wigler, M.H. 1995. Multiple Ras functions can contribute to mammalian cell transformation. Cell 80: 533-541.

White, M.A., Vale, T., Camonis, J.H., Schaefer, E., and Wigler, M.H. 1996. A role for the Ral guanine nucleotide dissociation stimulator in mediating Ras-induced transformation. $J$. Biol. Chem. 271: 16439-16442.

Wolthuis, R.M. and Bos, J.L. 1999. Ras caught in another affair: The exchange factors for Ral. Curr. Opin. Genet. Dev. 9: 112-117.

Wolthuis, R.M., de Ruiter, N.D., Cool, R.H., and Bos, J.L. 1997. Stimulation of gene induction and cell growth by the Ras effector Rlf. EMBO J. 16: 6748-6761.

Zarbl, H., Sukumar, S., Arthur, A.V., Martin-Zanca, D., and Barbacid, M. 1985. Direct mutagenesis of Ha-ras-1 oncogenes by N-nitroso-N-methylurea during initiation of mammary carcinogenesis in rats. Nature 315: 382-385. 


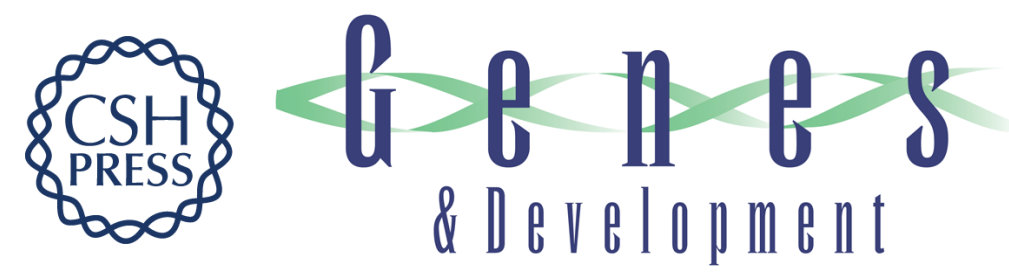

\section{Distinct requirements for Ras oncogenesis in human versus mouse cells}

Nesrin M. Hamad, Joel H. Elconin, Antoine E. Karnoub, et al.

Genes Dev. 2002, 16:

Access the most recent version at doi:10.1101/gad.993902

References This article cites 85 articles, 35 of which can be accessed free at: http://genesdev.cshlp.org/content/16/16/2045.full.html\#ref-list-1

License

Email Alerting

Receive free email alerts when new articles cite this article - sign up in the box at the top Service right corner of the article or click here.

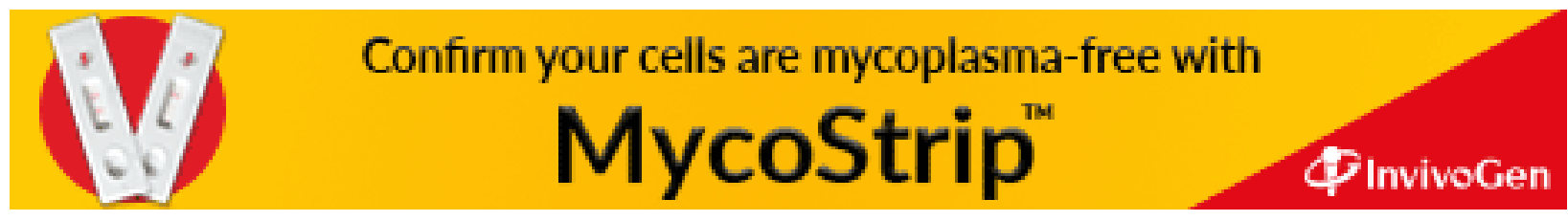

